\title{
Entre la agencia y el estigma: negociaciones identitarias de brasileñas/os en Santiago de Chile desde una perspectiva Biográfica-Interseccional ${ }^{*}$
}

\author{
Ariany da Silva Villar** \\ Beatriz Padilla*** \\ Dariela Sharim ${ }^{* * * *}$
}

\begin{abstract}
Resumen
Este artículo explora cómo las intersecciones de género, raza y nacionalidad inciden en la experiencia migratoria y en los procesos identitarios de brasileños/as residentes en Santiago de Chile. Para ello, aplicamos un análisis Biográfico-Interseccional a sus trayectorias migratorias obtenidas a través del método de los relatos de vida, entrevistas en profundidad y fotohistorias (fotografía participativa). Este análisis sugiere que la corporalidad de la mujer brasileña, especialmente representada por la mujer afrodescendiente, se torna, al mismo tiempo, ícono de una brasilidad sexualizada y dispositivo de agencia y de negociaciones identitarias.
\end{abstract}

Palabras clave: Migración brasileña, Migración sur-sur, Interseccionalidad, Corporalidad, Identidad.

\footnotetext{
* Recebido em 09 de novembro de 2020, aceito em 27 de outubro de 2021.

** Candidata a doctora en Psicología por la Pontificia Universidad Católica de Chile (PUC-Chile); integrante del Laboratorio Interdisciplinario de Subjetividad y Cambio Social (LISCS-Chile), patrocinada por el Centro de Estudios para el Conflicto y la Cohesión Social (COES) y becaria de la Agencia Nacional de Investigación y Desarrollo (ANID) (CONICYT-PFCHA/Doctorado Nacional/2017-21171315) en Santiago, Chile. avillar1@uc.cl / https://orcid.org/0000$\underline{0001-5275-9033}$

*** Profesora asociada en el Departamento de Sociologia y directora del Institute for the Study of Latin American and the Caribbean (ISLAC) en la University of South Florida, EUA; investigadora en el Centro de Investigaciones y Estudios de Sociología del Instituto Universitário de Lisboa (ISCTE-IUL), Lisboa, Portugal. padillab@usf.edu / https://orcid.org/0000$\underline{0002-2359-3369}$

**** Profesora titular en el Departamento de Psicología de la PUC-Chile, coordinadora del Laboratorio Interdisciplinario de Subjetividad y Cambio Social (LISCS-Chile); investigadora del Centro de Estudios para el Conflicto y la Cohesión Social (COES), Santiago, Chile. dsharim@uc.cl / https://orcid.org/0000-0001-8926-3349
} 
Between Agency and Stigma: Identity Negotiations of Brazilians In Santiago, Chile from a BiographicalIntersectional Approach

\begin{abstract}
This article explores how intersections of gender, race, and nationality influence both the migration experience and identity processes of Brazilians living in Santiago, Chile. We use a biographicalintersectional analysis of their migratory trajectories collected with the Life Stories Method, in-depth interviews, and Fotohistorias (participatory photography). The analysis suggests that Brazilian female corporality, represented especially by Afro-descendant women, becomes simultaneously an icon of a sexualized Brazilianness and a device of agency and identity negotiations.
\end{abstract}

Keywords: Brazilian migration, South-South Migration, Intersectionality, Corporality, Identity. 


\section{Introducción}

Chile se ha convertido en país de destino de nuevos flujos migratorios internacionales, principalmente provenientes de Sudamérica y el Caribe (Doña-Reveco, 2018). El porcentaje de población de origen inmigrante pasó de un 0,82\% en 1990 a un 7,67\% de la población total a fines de 2019, llegando a 1.492.522 inmigrantes (Instituto Nacional de Estadísticas de Chile [INE], 2020a) de los cuales un 59,4\% reside en la Región Metropolitana de Santiago (INE, 2020b:35), y un $90,9 \%$ provienen de países latinoamericanos (INE, 2020a:21). Entre ellos, Brasil ocupa el décimo puesto y el tercero con mayor índice de feminización (INE, 2020a).

Según Stefoni y Stang (2017), en los últimos 20 años, los estudios migratorios en Chile han visibilizado las experiencias de las mujeres sudamericanas, denunciando las limitantes de los nichos laborales existentes (Stefoni, 2009; Stefoni y Fernández, 2011), y consolidando los estudios sobre la mujer migrante (Soto-Alvarado, 2020:14). Más recientemente, el incremento significativo de las migraciones provenientes de Haití, Colombia y Venezuela se ha traducido en cambios que han reconfigurado racial, étnica y culturalmente tanto las ciudades chilenas como el enfoque de los estudios migratorios (Rojas-Pedemonte, Amode y Vásquez-Rencoret, 2015; Tijoux, 2012; 2016). Por ello, la emergencia de investigaciones que promueven una perspectiva interseccional para "comprender de manera más densa la vinculación entre el género, la clase y los procesos de etnización y racialización" (Stefoni y Stang, 2017:114) en la experiencia migratoria han ganado centralidad.

En este sentido, el presente artículo explora cómo las intersecciones de diferentes categorías de diferenciación social ${ }^{1}$, especialmente género, raza y nacionalidad (Hill-Collins, 2002), inciden en la experiencia migratoria y en los procesos identitarios de brasileños/as residentes en Santiago de Chile. Desarrollamos un análisis "Biográfico-Interseccional" de dicha inmigración, articulando en un mismo estudio dos enfoques teórico-metodológicos: el Enfoque Biográfico, que se interesa por la historia subjetiva como eje articulador de la relación sujeto-sociedad (De Gaulejac, 1996; Sharim, 2005); y la Interseccionalidad, que destaca cómo el cruce de categorías de diferenciación son estructuras sociales opresoras que producen desigualdades de oportunidades y de experiencias en la vida para los sujetos (Anthias, 2012; Hill-Collins, 2002). Con la combinación de enfoques, buscamos establecer conexiones entre contextos, estructuras sociales y agencia ${ }^{2}$ subjetiva al considerar que cada persona es sujeto activo de su historia dentro de ciertos marcos socioculturales, una agencia que es negociada y que se ejerce en las relaciones de poder de manera desigual (Bürkner, 2012; Domínguez y Contreras, 2017; Ortner, 2016).

En los siguientes apartados profundizamos en la teoría interseccional para discutir cómo la nacionalidad brasileña se constituye como categoría de diferenciación en las experiencias de vida y en los procesos identitarios de inmigrantes brasileñas/os a través del imaginario internacional de brasilidad. Posteriormente presentamos la noción de identidades intersticiales para pensar la (re)producción identitaria entre agencia y sujeción en el contexto migratorio internacional, analizando los casos de los/las participantes en nuestra investigación, y señalando las principales categorías de diferenciación que emergen en los relatos para entender sus efectos en las negociaciones identitarias subjetivas. Finalmente, destacamos cómo el uso de las corporalidades en dichas negociaciones se hizo más evidente en los casos de mujeres afrobrasileñas.

\footnotetext{
1 Categorías construidas socialmente, entendidas como "marcadores sociales de la diferencia" (Moutinho, 2014, citada en Padovani, 2017:7), que jerarquizan a las personas y producen desigualdades sociales.

2 Nuestra comprensión de agencia se acerca a lo discutido por Ortner (2016). La agencia tendría doble cara: por un lado, la capacidad de todo sujeto de conducir proyectos, construidos culturalmente, que pueden sostener o transformar los marcos socioculturales hegemónicos; por otro lado, la agencia es el "actuar en un marco de relaciones de desigualdad social, de asimetría y fuerza" (Ortner, 2016:161). Por lo tanto, las personas no se encuentran totalmente sujetas a las estructuras sociales, pero tampoco su agencia es libre del contexto cultural en el cual se encuentran. Destacamos la importancia de las relaciones de desigualdad de poder que sostienen las estructuras sociales y que establecen desigualdades en las formas y alcances de la agencia subjetiva, explicadas por Ortner (2016) a través del rol subalterno de la mujer en diversas sociedades. Esa concepción de agencia se vincula con los estudios feministas de la migración, en los cuales se desarrolla la idea de que la intersección de diferentes clasificaciones sociales define posiciones sociales a los sujetos en la experiencia migratoria, en que el género es un eje fundamental de producción de desigualdades (Anthias, 2012; Bürkner, 2012; Pessar y Mahler, 2003).
} 


\section{Migración brasileña desde la perspectiva interseccional}

La interseccionalidad busca comprender los efectos del cruce de una variedad de ejes de diferenciación social -género, "raza", clase, sexualidad, etnia, nacionalidad, entre otros- en un determinado contexto y momento histórico (Brah y Phoenix, 2004:76). Emerge históricamente a partir de las contribuciones del feminismo negro de Angela Davis (Gomes, 2018) y se desarrolla desde diferentes teóricas. La perspectiva interseccional clásica de Crenshaw (1991) analiza, desde el derecho, cómo la intersección de "raza", género y clase están implicadas en la condición de desventaja de mujeres afrodescendientes y latinas (mujeres de color) en los Estados Unidos. A su vez, Hill-Collins (2002), desde la sociología, estudia la intersección de categorías sociales como matrices de opresión, agregando la sexualidad y la idea de nación como categorías de diferenciación en la experiencia de la mujer afrodescendiente.

La teoría interseccional se amplía con el feminismo postcolonial, que inserta la nacionalidad y las relaciones coloniales a la discusión. McClintock (2010) discute sobre la paradoja del borrado de la mujer como agente de construcción de la nación -su vínculo con el Estado (ciudadanía) es consolidado a través del matrimonio (vínculo con un hombre en la constitución de la familia)- que coexiste con el uso de la mujer como símbolo de la nación en el contexto postcolonial occidental. Ese enfoque también aparece en las contribuciones de Brah (2011) en su cartografía de la diáspora, que incluye el debate sobre la relación colono-colonizado y de la racialización -la construcción de una jerarquía de las apariencias físicas (especialmente el color de la piel) que, al ser naturalizada, justificaría la existencia de la nación- la problemática de las diferencias de posición en la jerarquía social entre grupos subordinados/oprimidos. En ese sentido, la interseccionalidad debe ser situada en un lugar y tiempo específicos, considerando la "racialización diferencial"3 en cada contexto y para cada trayectoria colectiva (Brah, 2011:217). Ambas autoras convergen en la relación indisociable entre género-nación-raza-colonialidad en la construcción de la idea de nación en excolonias europeas, en los efectos de ello en la experiencia subjetiva y colectiva. Para estas autoras, la forma dicotómica sobre la cual se constituyeron las naciones (a partir de la dicotomía blanco/no-blanco (racialización), hombre/mujer (diferencias de género), y de la relación de sumisión de los segundos a los primeros, construye un sentido de unidad o hermandad nacional que une hombres blancos. Por lo mismo, las mujeres de color (de las colonias) fueron invisibilizadas como agentes en la resistencia política contra los colonizadores, aunque su contribución sea innegable (Brah, 2011; McClintock, 2010).

La perspectiva interseccional permite identificar cómo la migración brasileña encuentra en los territorios de destino diferentes imágenes sobre qué significa ser de esa nacionalidad. Togni (2014), en su estudio sobre jóvenes brasileños no-blancos residentes en el barrio de Cacém/Lisboa, utiliza la interseccionalidad para cuestionar la relevancia de las fronteras nacionales en la constitución de la trayectoria subjetiva transnacional y agrega la religión y el lugar de origen y de destino en los cuales transitan los/las migrantes como categorías de diferenciación, entendiendo la migración como experiencias de movilidad múltiples: económicas, de roles sociales, espaciales, de posiciones subjetivas.

En los países del norte global en que la migración brasileña es numéricamente relevante, las personas de Brasil pasan por un proceso de etnización y racialización en que la categoría de país de origen es yuxtapuesta a características culturales y rasgos físicos, respectivamente, produciendo una determinada brasilidad (Padilla; Oliveira Fernandes y Gomes, 2017).

Con relación al género, una de las categorías más determinantes de las desigualdades sociales en la migración (Magliano, 2015), el cuerpo de la mujer brasileña ha sido asociado a un imaginario colonial luso-tropical, el cual sufre modificaciones a lo largo del siglo XX hasta ser integrado a un proyecto político para atraer el turismo internacional a Brasil en los años 80 (Padilla, 2007b; Piscitelli, 1996). En dicho proyecto, ciertos elementos de la cultura afrobrasileña fueron primero nacionalizados y luego globalizados, como la samba y el carnaval, y sintetizan una corporalidad

\footnotetext{
3 Se refiere a "un concepto para analizar procesos de multi-posicionalidad relacional dentro y a través de las formaciones de poder marcadas por la articulación de una forma de racismo con otra, y con otros modos de diferenciación" (Brah, 2011:217).
} 
sensual que resalta la disponibilidad sexual de las mujeres (afro)brasileñas, cuyo ícono es la figura de la mulata "hipererotizada como símbolo del carnaval"4 (Gomes, 2013:876).

Estas imágenes fueron ampliamente divulgadas en el escenario internacional a través de las telenovelas brasileñas exportadas -como Gabriela, Cravo e Canela de Jorge Amado (Padilla, 2007b) - y de la publicidad oficial del gobierno brasileño, que utilizaba imágenes de los cuerpos de brasileñas semidesnudas en escenarios tropicales como objeto de atracción turística (Gomes, 2013). Se ha generado internacionalmente un imaginario erótico, exótico y altamente sexualizado (Gomes, 2013; 2018; Guizardi, 2013; Padilla, 2007b) en torno al cuerpo de la mujer brasileña, que sigue siendo reproducido tanto en el turismo sexual (Piscitelli, 2011) como en las trayectorias de vida de las brasileñas alrededor del mundo, haciendo de la intersección de género-nacionalidad un nudo determinante en la experiencia migratoria, tal vez con matices dependiendo del contexto geográfico.

Por otra parte, la construcción del "negro" en las colonias fue una manera de justificar la marginalización y la esclavización de las personas no-europeas indígenas y afrodescendientes; a quienes se les atribuía el lugar de la barbarie y del instinto sexual (Padilla y Gomes, 2012). Posteriormente, en la construcción de la idea de identidad nacional brasileña durante el siglo XX, el mito de una democracia racial intentó fundar una raza/identidad brasileña nacida de la mezcla de las "razas" blanca, negra e indígena, siendo un derivado directo del imaginario colonial articulado por Gilberto Freyre (Padilla, 2007b). Esto ha hecho que la "raza" y la racialización sean una temática relevante que genera una gran complejidad identitaria para brasileños/as (Joseph, 2015), tanto dentro como fuera de Brasil.

Al tornarse inmigrantes en otros países, las personas oriundas de Brasil enfrentan diversos estereotipos en torno a qué significa ser brasileño/a. Los procesos de estereotipificación les atribuyen características comportamentales, culturales y físicas relacionadas con la belleza, la simpatía, la alegría y la disponibilidad sexual (Piscitelli, 2007; 2008). En ciertos países del norte global, son "clasificados, inferiorizados, esencializados, estigmatizados ${ }^{5}$ y naturalizados a partir de supuestas características físicas, culturales y comportamentales comunes, como si compusiesen una 'raza"” (Padilla y Gomes, 2012:7).

Gomes (2018) destaca la inseparabilidad del género y la raza en la comprensión de la experiencia de mujeres migrantes desde las excolonias hacia las ex metrópolis. Especialmente en Portugal, ex metrópoli colonial de Brasil, las mujeres portuguesas-blancas son clasificadas como las madres, vírgenes y puras, mientras que a las mujeres brasileñas se les reserva el lugar del cuerpo pecaminoso, sexualizado, una amenaza a la familia tradicional portuguesa. Ese imaginario colonial sobre el cuerpo de la mujer brasileña estaría presente en el cotidiano de las relaciones sociales entre migrantes y locales, pero también en los medios de comunicación y en documentos oficiales del Estado portugués (Gomes, 2018). El proceso de racialización es transversal a las mujeres brasileñas, pero es aún más evidente en el caso de las mujeres brasileñas "morenas", por el cual la dimensión racial asociada al género y nacionalidad les impone barreras sociales difíciles de superar (Gomes, 2013; Padilla, 2007b; Piscitelli, 1996).

Además, los cuerpos de las mujeres brasileñas se han tornado marcadores sociales de desigualdades y de la división sexual del trabajo en el norte global, donde ellas ocupan nichos laborales específicos relacionados con la corporalidad (bailarinas de ritmos brasileños), con la estética, la atención al público, al servicio doméstico y al cuidado (Oliveira-Assis, 2014; Padilla, 2007a; Gomes, 2013; Guizardi, 2013; Padilla y Gomes, 2012).

\footnotetext{
4 Otras autoras discutieron este proceso anteriormente, como Giacomini (1991).

5 Para Goffman (2006), el estigma es la invalidación de la identidad social de un sujeto en las relaciones sociales e interpersonales en un contexto histórico específico. Para definir los grupos o personas estigmatizadas, una sociedad establece criterios de normalidad/anormalidad; el estigma es lo que hace dicha anormalidad identificable, una marca que puede ser física, conductual (comportamiento desviante) o la pertenencia a un grupo étnico o nacional (Goffman, 2006). Juliano (2003) entiende la estigmatización como componente de un proceso de inclusión/exclusión social en el cual algunos grupos son considerados parte de la sociedad y otros, como alteridad amenazante. Los sujetos o grupos estigmatizados son en general esencializados (resumidos a algunas de sus características), y se les reserva la imposibilidad de una integración social plena (Juliano, 2003:63). Ejemplos de estigmatización son reportados en los estudios de Malheiros y Padilla (2014) y de Padilla y Gomes (2012) sobre mujeres brasileñas migrantes en Portugal.
} 
Sin embargo, ellas también encuentran en la migración la posibilidad de aumentar su capacidad de agenciamiento o agencia en las sociedades receptoras, aunque ser sujetos de su propria historia sea una experiencia negociada con el entorno (Domínguez y Contreras, 2017). Esto significa que, a pesar de las limitaciones que un determinado contexto pueda presentar, las migrantes toman decisiones, plantean objetivos y diseñan estrategias para alcanzar sus metas individuales y colectivas a través de prácticas de resistencia, subvirtiendo las normas o usándolas de otra manera (Domínguez y Contreras, 2017).

Un ejemplo de ello es cómo algunas brasileñas asumen el protagonismo del proceso migratorio subvirtiendo el estigma de sexualización de sus cuerpos como estrategia de inclusión económica y social en las sociedades receptoras. En Portugal, las brasileñas han creado espacios de emprendimiento, especialmente en ciertos nichos, como el "mercado de la belleza", mejorando sus condiciones de vida material y enriqueciendo la sociedad de destino con otros patrones de belleza corporal (Malheiros y Padilla, 2014). Asimismo, muchas brasileñas lucharon colectivamente por la desfetichización y el reconocimiento de sus voces a través del "Manifesto contra o preconceito às Mulheres Brasileiras em Portugal', realizado en 2011 en contra de la discriminación que sufren cotidianamente (Padilla y Gomes, 2016), o más recientemente el movimiento "As brasileiras não se calam" al reiterar la misma denuncia.

En este sentido, el estudio de la inmigración brasileña en Santiago de Chile nos ofrece la posibilidad de investigar en el contexto sudamericano, simultáneamente, los complejos efectos de las categorías sociales en la vida subjetiva y la agencia que los/as migrantes despliegan en la construcción de su proyecto migratorio y sus identidades.

\section{Negociaciones identitarias en contexto migratorio}

Según Hill-Collins (2002), las intersecciones entre diversas categorías sociales, cuando se materializan en discursos, prácticas y estructuras sociales, constituyen matrices de dominación ${ }^{6}$ que ubican al sujeto en una determinada posición social en cada contexto sociocultural, siendo las estrategias de poder las que las materializan. Afirma que, cuando se transita entre diferentes matrices de dominación, la persona tiene nuevas oportunidades de ejercer agencia sobre su propia vida, así como aparecen nuevas formas de opresión con las cuales debe negociar sus experiencias (Hill-Collins, 2002). Por ello entendemos que, al migrar, las personas transitan entre diferentes sociedades y también entre diferentes matrices de dominación.

Peregrinar entre matrices de dominación puede dar espacio a la producción de narrativas identitarias diferentes a las que se producen en el país de origen. Primeramente, porque la sociedad receptora se organiza en categorías sociales que suelen ser disímiles a las que componen las matrices de dominación en la sociedad de origen, promoviendo otros encuentros identitarios con la migración que involucran también identidades culturales, étnicas y sociales diversas. Si consideramos que las identidades son producidas en el encuentro con la diferencia/alteridad a través de la vida narrada (Ricoeur, 2006), en que el reconocimiento de sí mismo pasa por el reconocimiento de un otro social dominante (Benjamin, 1988), podemos decir que la migración internacional es un catalizador de procesos identitarios subjetivos: complejiza el proceso de producción identitaria al ampliar los encuentros con la diferencia en las experiencias de vida y al agregar la sociedad de llegada como campo de lucha activa por el reconocimiento (así como lo sigue siendo la sociedad de origen), permitiendo la construcción de otras narrativas sobre la propia vida, luego, otras identidades.

Entendemos que los/las migrantes no dejan atrás las identidades que construyeron antes de migrar, sino que habitan simultáneamente la comunidad sociocultural de origen y de llegada, transitando constantemente entre ellas en sus cotidianos (Stefoni y Bonhomme, 2014). Las identidades que se construyen en la migración son más complejas que una combinación de elementos culturales de origen y de destino -como lo había sugerido Canclini (2008)- pues son

\footnotetext{
6 Aunque Hill Collins (2002) no trabaje este concepto con relación a la migración internacional, decidimos utilizarlo para comprender la complejidad de las realidades discursivas, materiales y socioculturales que enmarcan la vida en sociedad de manera disímil en cada contexto social.
} 
continuamente negociadas en cada experiencia vivida $y$, por lo tanto, están en constante transformación.

En este sentido, utilizamos la noción de identidades intersticiales como modo de entender las identidades personales como procesos de identificación (Hall, 200), narrativas de si ${ }^{7}$ producidas y continuamente negociadas en el intersticio entre [in between] (Bhabha, 1998) marcos socioculturales y matrices de dominación de las sociedades con las cuales los/las migrantes se relacionan. La noción de identidades intersticiales enmarca nuestra comprensión de identidades, y direcciona nuestra mirada analítica hacia las tensiones y negociaciones por las cuales brasileños/as en Santiago (re)producen narrativas de sus vidas, ampliando (o no) sus capacidades de agenciamiento. El énfasis en las identidades como producciones narrativas nos condujo, como se verá a seguir, a una metodología narrativa de producción de datos.

\section{Notas metodológicas}

Esta investigación se enfoca en los procesos identitarios según se reflejan en las experiencias migratorias subjetivas, recogidas a través del Método de los Relatos de Vida (De Gaulejac, 1996; Rheaume, 1996; Sharim, 2005), de entrevistas en profundidad y de Fotohistorias, técnica de fotografía participativa activada como dispositivo de producción de narraciones (Gómez, 2016; 2017; Yefimova, Neils, Newell, Gómez, 2015). Asimismo, utilizamos Cuadernos Reflexivos (Bedregal, Besoain, Reinoso y Zubarew, 2017) como dispositivo de escucha para el registro de informaciones no verbales producidas en los encuentros de investigación con cada participante. En base a dichos instrumentos, construimos un conjunto de casos lo más diverso posible en cuanto a las categorías de diferenciación social más incidentes en la migración - género, raza/etnia, clase social, según otras investigaciones (Magliano, 2015). De un total de 16 casos, 8 son de sexo masculino y 8 de sexo femenino ${ }^{8}$, con edades comprendidas entre 22 y $53^{9}$ años, con al menos 1 año de residencia en Santiago ${ }^{10}$, y provenientes de diferentes regiones de Brasil (nordeste, centrooeste, sudeste y sur).

El trabajo de campo tuvo lugar durante el segundo semestre de 2018 y el primer semestre de 2019, y combinó los métodos de producción de datos en tres etapas. i.) Primer encuentro: cada participante contó libremente su historia de vida y migración (Método de los Relatos de Vida); ii.) Etapa de Revisión: investigadoras y participantes revisaron, por separado, la transcripción del primer encuentro. Simultáneamente, para articular con el método de las Fotohistorias, se le solicitó a cada participante que sacase fotos de su cotidiano para traer al próximo encuentro; iii.) Segundo encuentro de profundización: se preguntó a los/las participantes si querían agregar algo a sus relatos de vida; después, se realizaron entrevistas en profundidad sobre los hitos de su historia que debían ser ahondados y sobre las categorías de diferenciación que aparecieron como relevantes en el relato de vida del/la participante. Al final del segundo encuentro, se invitó a los/las participantes a comentar el significado de las fotografías que trajeron (Fotohistorias). La comunicación fue en portugués (idioma de origen de los/las participantes y de la investigadora-entrevistadora), las entrevistas fueron grabadas y posteriormente transcriptas, y se incorporó un Consentimiento Informado escrito.

Examinamos las transcripciones a través de un proceso analítico Biográfico-Interseccional en dos etapas: i.) Etapa Biográfica: buscamos entender cómo cada sujeto negocia sus identidades entre los contextos socioculturales por los cuales transita (relación sociedad-individuo encarnada en su biografía (De Gaulejac, 1996; Sharim, 2005)); ii.) Etapa Interseccional: analizamos transversalmente los casos e identificamos las categorías de diferenciación sobresalientes en la producción de

\footnotetext{
7 Nos acercamos a la noción de identidades narrativas de Ricoeur (2006) al entender las identidades como constantemente producidas a través de relatos de la propia vida.

8 Sobre las identidades de género, todas las personas participantes se identificaron con su sexo biológico, como hombres y mujeres.

9 El promedio de edad de los/las participantes es de 34 años.

${ }^{10} \mathrm{El}$ promedio de tiempo de residencia en Santiago es de 5 años.
} 
desigualdades en la experiencia migratoria de los/las participantes y sus procesos identitarios subjetivos.

Como resultado de los análisis biográfico-interseccionales, identificamos diferentes intersecciones de categorías de diferenciación incidentes en los proyectos migratorios y los procesos identitarios subjetivos de brasileños/as en Santiago, de las cuales destacamos el género-nacionalidad y el género-raza-nacionalidad. A continuación, presentamos cómo esas categorías se articulan en la composición de matrices de dominación relevantes en la experiencia subjetiva de migración de los/las participantes y, con énfasis en la experiencia de dos mujeres afrobrasileñas, discutimos cómo estas participantes negocian narrativas sobre sí mismas con dichas matrices para ampliar su capacidad de agencia.

\section{Marcadores de desigualdad: intersección género-nacionalidad brasileña}

El género ha sido entendido como un conjunto de construcciones sociales catalizadoras de desigualdades que distinguen y jerarquizan las personas por su sexo biológico, y establecen a partir de ello, oportunidades y limitaciones en el cotidiano de la vida en sociedad, en que las mujeres ocupan una peor posición social (Nawyin, 2010). Para Lugones (2008:78), se refiere a un sistema de dominación caracterizado por la dicotomización entre hombre/mujer, "el heterosexualismo, y el patriarcado". La construcción de diferencias de género es lo que sostiene la dominación colonial eurocéntrica incluso con la independización de las colonias (Lugones, 2008) y está en la base de la idea de nación en Occidente (McClintock, 2010), conforme vimos anteriormente.

En las migraciones internacionales, en particular, el género produce diferencias en los motivos por los cuales las personas migran, en los sentidos que atribuyen a la migración, en las ventajas y desventajas económicas y de inserción social a las cuales una persona puede acceder en la sociedad de destino, entre otros (Gissi Barbieri y Martínez Ruiz, 2018). Esas diferencias hacen que el relato de sus biografías y su producción narrativa, elemento fundamental de producción identitaria, sean generizados (Martinez-Guzmán y Montenegro, 2014) también en el proceso migratorio. De este modo, identificamos cuatro principales diferencias entre participantes en la manera de narrar su proyecto y experiencia migratoria de acuerdo a su posición en las relaciones de género.

La primera diferencia está en las motivaciones para migrar y el eje central en torno al cual esas personas relataron sus historias. Para las mujeres brasileñas participantes, la vida afectiva, amorosa y familiar tienen gran importancia en la manera como articulan sus relatos de vida, presentadas desde la primera entrevista y explayadas en el segundo encuentro con las fotografías. La vida en pareja, la posibilidad de formar una familia en Chile y el cuidado de los hijos/as aparecieron como elementos centrales: el proyecto de migrar para acompañar al novio o marido es una experiencia común para 4 de las 8 participantes. Sobre la maternidad, la participante que es madre de hijos nacidos en Brasil (Ana María) cuenta que solo pudo dejar el país cuando ellos se tornaron adultos. Las que son madres de hijos/as nacidos en Chile (como María, Tania y Camila), por otro lado, comentaron su preocupación e imposibilidad de volver a Brasil por tener hijos/as nacidos/as en el extranjero. En esos casos, los hijos/as son anclas que las aferran a Chile, dándoles cierto sentido de pertenencia al país de destino a la vez que las inmoviliza, no permitiendo regresar al país de origen.

Al contrario, los relatos de vida de los hombres se centraron en su desarrollo profesional: 6 de ellos narraron su migración a Santiago como una apuesta para una mejor condición socioeconómica. Entre algunos entrevistados de clase media y media alta, la familia aparece en sus relatos muy posteriormente, solo en el segundo encuentro, cuando compartieron las fotos seleccionadas, mostrando sus parejas e hijos/as. Asimismo, los hombres no relataron ninguna preocupación sobre la restricción de la movilidad transnacional como consecuencia de la paternidad. Sin embargo, durante el ejercicio de las fotohistorias, apareció entre ellos la intención de identificarse y ser identificados como buenos padres, lo que significaría dedicar tiempo de calidad a sus seres queridos, conciliando la vida familiar con el crecimiento profesional. En este punto, la narrativa sobre el éxito profesional y la de ser un buen padre parecen no coexistir sin tensiones, como apareció en el relato de Daniel, que construyó la narrativa familiar en su segunda entrevista destacando las dificultades cotidianas al yuxtaponer el rol de empresario y el rol de padre. 
Es necesario destacar que no todos los hombres migraron por trabajo, así como no todas las mujeres migraron por amor. Encontramos, en torno a algunos casos de experiencias masculinas de migración, proyectos migratorios impulsados por una relación amorosa (relatos de Pablo y Luís), así como casos de mujeres que migraron motivadas por el crecimiento profesional (relatos de Camila, Manuela y Bruna), lo que podría indicar cambios en las relaciones de género en el contexto migratorio.

La segunda diferencia se refiere a que la mayoría de las mujeres entrevistadas cuentan que en algún momento de su historia de vida sufrieron algún tipo de violencia de género vinculada a su proceso migratorio, lo que no aparece en el relato de los hombres. Las participantes María, Ana María, Tania y Camila relataron haber sufrido episodios de violencia física. Estas situaciones se dieron tanto en la ciudad de origen, convirtiéndose en el motivo de migración internacional, como en la sociedad de destino, en momentos de vulnerabilidad como inmigrantes en Santiago. En el caso de Ana María, por ejemplo, la violencia doméstica fue el principal motivo de su partida. Como trabajadora doméstica en Brasil, huyó a Chile escapando del exmarido que la agredió física y psicológicamente durante 20 años. Cuando sus hijos se tornaron adultos, escapó de esa situación, migrando a Santiago para trabajar como empleada doméstica interna. Migrar a otra ciudad de Brasil, según ella, no sería suficiente para salvaguardar su vida.

Ser mujer migrante ha sido un desafío importante también en el ámbito público. En el relato de Manuela, estudiante de doctorado y becaria en una investigación de una importante universidad chilena, la misoginia aparece explícitamente en su ambiente laboral. Sin embargo, fue el hecho de ser mujer-migrante lo que la obligó a tener que soportar la discriminación y mantenerse en el empleo por más tiempo que sus compañeras chilenas.

Mucha misoginia, mucho machismo, mucha humillación. [...] Mi exjefe es misógino declarado, dice que no cree que las mujeres puedan desarrollar su potencial intelectual al $100 \%$, que existe una limitación emocional [...]. Entonces la gente se iba, desaparecía. [...] ¿Y yo no podía, cierto? Era mi oportunidad, no podría darme el lujo de abandonar [la investigación], porque si lo hiciera, significaría abandonar el doctorado, perder la beca [...] (Manuela, Entrevista 1:24).

La tercera diferencia es que las mujeres relataron sufrir con el estigma de la sexualización especialmente por ser de nacionalidad brasileña, lo que estuvo ausente en el relato de los hombres. El estereotipo de sexualización relacionado con el cuerpo de la mujer brasileña en Santiago también fue expresado como un modo de violencia simbólica en la convivencia pública, y fue una temática común en el relato de varias participantes, quienes dicen haber sido afectadas tanto en la vida personal como profesional. Algunas participantes cuentan que, para pasar desapercibidas y evitar ser erotizadas, deben cambiar su forma de ser (alegres y ruidosas), su forma de vestirse (no ponerse ropa corta, apretada o de colores) y sus formas de expresarse (hablar bajo para no llamar la atención).

Sin embargo, las mujeres son las que relatan más explícitamente cómo la migración les ha dado la posibilidad de ejercer mayores niveles de agencia sobre su propia vida: dicen sentir mayor libertad para tomar decisiones y emprender proyectos en la sociedad de destino, y por ello están más satisfechas consigo mismas en Santiago que en Brasil. Este discurso no surgió en los participantes hombres. Helena, una joven que vino acompañando a su novio, pudo reinventarse profesionalmente, y de publicista pasó a trabajar también como instructora de yoga. A Bruna, Manuela y Camilla, se les abrieron posibilidades de trabajo que les ofrecieron mejores condiciones de vida e independencia financiera. Ana María, que migró huyendo del exmarido violento, relata que ha podido ampliar los espacios que transita, conocer lugares y nuevas culturas, hacer nuevas amistades y descubrir relaciones amorosas sin violencia.

Finalmente, la intersección género-nacionalidad brasileña en el contexto santiaguino muestra cómo habitar un cuerpo de hombre o de mujer acarrea diferencias importantes en la experiencia migratoria. El imaginario internacional en torno al cuerpo de las mujeres brasileñas y el estereotipo de sexualización se traduce en un riesgo inminente de violencia, influyendo en cómo se comportan y se posicionan en la sociedad de destino, lo que las lleva a intentar disimular su nacionalidad. Sin embargo, no todas las mujeres entrevistadas pudieron optar por dichas estrategias. Las mujeres 
afrobrasileñas, cuyas experiencias e identidades también son atravesadas por el color de piel, utilizan otros medios para mitigar la discriminación, incluso, hacer resaltar su nacionalidad.

\section{Corporalidades afrobrasileñas: intersección género-raza-nacionalidad}

La raza es una categoría que emerge en Occidente en el siglo XVI para jerarquizar a las personas por sus características físicas y justificar la esclavitud y explotación de pueblos africanos e indígenas por los europeos en los territorios coloniales (Almeida, 2019). Esa categoría reordenó las relaciones de dominación en Occidente a partir de la idea de superioridad natural de los blancos sobre los no-blancos, posibilitando que el colonialismo se haya diseminado profundamente en el tejido social (Lugones, 2008), y que sea la herencia primordial del período colonial en las sociedades modernas (Gomes, 2018). La idea de raza ha sostenido las naciones como comunidades imaginadas, uniendo a grupos muy diversos de personas en torno a una misma hermandad nacional masculina (McClintock, 2010). En ese contexto, la mujer queda al margen de la vida política y es considerada patrimonio de la nación (McClintock, 2010).

En este estudio, la raza surgió como una categoría esencial en la determinación de las narrativas de vida y migración de los/las participantes, principalmente los/las afrodescendientes. A diferencia de los/las participantes de tez clara, los/las participantes afrodescendientes incorporaron en sus relatos el racismo y la raza como parte de sus experiencias cotidianas antes y después de la migración, aunque los expresaron de distintas maneras dependiendo del contexto social en que se encontraban. En la sociedad de origen, Brasil, el racismo tendía a aparecer de manera más institucionalizada y estructurada, coartando las oportunidades de crecimiento personal y profesional de las personas racializadas. En Santiago, el racismo relatado es explícito y es vivenciado principalmente en las relaciones interpersonales.

En el caso específico de las participantes afrodescendientes, los relatos de Vida y Tania muestran cómo en sus vidas las experiencias de racismo se cruzan con la violencia de género, y con la sexualización y exotización de sus cuerpos (por ser brasileñas), haciéndolas ocupar un lugar social complejo en la matriz de dominación. Vida (40 años) y Tania (42 años) provienen de familias de clase socioeconómica baja, y vivían en barrios periféricos de Recife (Tania) y São Paulo (Vida). En ambos relatos, la lucha por superar las barreras que les impuso su posición social específica (mujer, afrodescendiente y pobre) es más relevante en las narrativas sobre sus identidades que la inmigración internacional en sí.

Vida describe un gran cambio de vida con relación a las generaciones anteriores de su familia, y en su relato la migración a Chile es una entre otras etapas en la construcción de sí misma como sujeto de su historia. Su madre y su padre fueron figuras clave que le influenciaron explícitamente para ser una profesional de éxito. Ellos, migrantes internos del nordeste de Brasil hacia la ciudad de São Paulo, vivieron con su única hija en un barrio periférico pobre, trabajando de sol a sol para pagarle el colegio particular y un curso de inglés. Saber inglés, según cuenta, le cambió la vida y la distanció de la realidad de los que vivían en su barrio: ya a los 18 años, consiguió trabajo en una compañía aérea, lo que a su vez le posibilitó costear dos carreras universitarias (Turismo y Secretariado) y vivir durante dos años en los Estados Unidos.

En su relato, pone en evidencia que lo que motivaba a sus padres a invertir en su educación era la idea de que su hija única no se convirtiera en un caso más de la profecía de autorrealización: evitaban que Vida reprodujera el estereotipo de mujer-negra-periférica, asociado a la criminalidad, la hipersexualidad, el embarazo precoz y la falta de calificaciones, o que fuera parte del nicho de trabajo étnico-racial vinculado a ser artista, bailarina, músico o deportista. Como resultado de la apuesta de sus padres, Vida tuvo una educación que le abrió puertas en los ambientes de personas de clase media alta en São Paulo; así, pudo percibirse a sí misma como capaz de conquistar el mundo y "hacer algo muy grande" de su vida (Vida, Entrevista 1, pár. 16).

Sin embargo, para escapar de los estereotipos racistas con los cuales convivía en Brasil, Vida cuenta que tuvo que dejar de lado la música y las artes, con las cuales se identificaba, para dedicarse al trabajo formal y mejor remunerado desde temprana edad. En ese contexto, migrar a Chile fue un proyecto que construyó con el objetivo de desarrollar los aspectos de su vida que quedaron en segundo plano durante muchos años en favor de lo profesional: a los 38 años, 
después de haber trabajado por décadas en el mundo corporativo, viajado por el mundo y alcanzado lo que para ella significaba el éxito profesional, se muda a Santiago para vivir con su novio chileno, y elige conscientemente formar una familia y construir un hogar. A través de su novio, músico profesional, Vida se ha reconectado con las artes como parte de su cotidianidad. Actualmente, acompaña a su pareja como instrumentista, tocando en diferentes ciudades de Chile, además de trabajar como profesora de inglés para una multinacional, otra de sus grandes pasiones.

El relato de Tania trae a la discusión una historia de vida que dista de la anterior. Originaria del nordeste brasileño, Tania viene de una familia monoparental pobre en la cual su madre, con poca escolaridad, trabajaba como costurera para mantener a 9 hijos/as. Por su condición de extrema pobreza, Tania tuvo que trabajar desde los 9 años vendiendo la comida que su madre preparaba. Trabajó también de nana durante toda su vida escolar, y con mucho esfuerzo logró terminar la educación media en una escuela pública. Estudiar una carrera universitaria era un sueño que nunca pudo realizar ya que la educación recibida no le permitió ingresar a una universidad pública y gratuita. Además, el racismo vivido en su cotidianidad tornaba su realidad laboral más difícil y las oportunidades para cambiar de vida eran aún más escasas.

A los 27 años, Tania conoció a un chileno en su ciudad y se casó con él. Al año de estar casados, el marido decidió volver a Chile para cuidar de los negocios de familia y de sus padres enfermos, y Tania tuvo que acompañarle con la promesa de que volverían a Brasil. Sin hablar español y sin dinero propio, al poco tiempo de llegar a Santiago, Tania quedó embarazada, y ese momento se tornó un hito en su vida: desde entonces, su marido pasó a agredirla físicamente. Tania relata que llamaba mucho la atención por ser afrodescendiente en una ciudad donde las personas de color no eran comunes en la época. Por celos, el exmarido la agredía y le prohibía salir sola a la calle; después del nacimiento de la hija en común, las encerró en su propia casa, al punto de ponerle un perro guardián para que la "comiera" en caso de querer salir. La situación de cautiverio duró tres años y la tía del marido fue cómplice.

Durante ese período, Tania descubrió que había una feria para personas mayores a una cuadra de su casa, donde hacían talleres de baile y artesanía, y le imploró al exmarido que la dejase ir. Con el tiempo, el exmarido le permitió participar en las actividades, y las personas mayores de la feria fueron la primera red de amistades que Tania hizo en Chile, siendo, según ella, el comienzo de su salvación. El cautiverio llegó a su fin cuando la madre de Tania la vino a visitar y descubrió "su cárcel de oro": tenía todas las condiciones materiales como nunca antes en su vida, pero vivía llorando, amargada, prisionera. Con la ayuda de la madre, Tania logró salir de esa situación y abandonar la casa, con su hija. Trabajó durante 4 años enseñando baile árabe profesional, fue profesora de zumba, hasta que una amiga la invitó a bailar samba profesionalmente, un trabajo que pagaba mejor que los anteriores.

Es interesante resaltar que Tania no relaciona lo que pasó entre ella y su exmarido con cuestiones raciales, sino con el mal carácter de él. Por lo tanto, para ella el racismo la perjudicó en su país de origen, mientras que en Chile el racismo no existiría, sino que impera el clasismo: te discriminan por ser pobre, no por el color de piel. Sin embargo, también contó cómo, en su primer contacto con los hombres en la sociedad de destino, su cuerpo la posicionaba como "una mujer cualquiera", sexualizada. Es su nacionalidad brasileña, evidenciada en el acento al hablar, lo que la posiciona de manera más favorable en relación a otras mujeres afrodescendientes provenientes de otros países.

[Chile] es clasista, pero racista, no. [...] Yo voy a decir lo que pasé aquí: yo entraba en un sitio acá, y yo veía que a veces los hombres me trataban como una cualquiera, hasta que yo hablara y se diesen cuenta que yo era brasileña. Porque desde entonces yo era colombiana, y colombiana aquí es como una prostituta [...]. Entonces, cuando veían mi color de piel, mi forma de vestir así, mi pelo, maquillaje, y venían y me trataban como si yo fuese una cualquiera, entonces, cuando yo hablaba: "ah, ella es brasileña", cambiaba el tono (Tania, Entrevista $1: 186)$.

Conforme Tania y otros/as participantes relatan, el racismo direccionado a inmigrantes en Chile está también condicionado por la nacionalidad de origen/identidad étnica. La nacionalidad brasileña es vista positivamente en el contexto santiaguino por sus elementos culturales y porque no 
es considerada un problema de migración: los brasileños/as son percibidos como turistas y no como inmigrantes en Chile, según varios participantes relataron. La buena recepción de la nacionalidad brasileña en Santiago habla, en realidad, de una jerarquía de nacionalidades/etnias que fue construida en los últimos años por las migraciones internacionales, según la cual los/las brasileños/as afrodescendientes están mejor posicionados socialmente que otros procedentes de distintos países latinoamericanos. En este contexto específico, ser identificado rápidamente como brasileña se tornó una estrategia clave para no ser confundida con personas de otras nacionalidades consideradas inferiores.

Tania relata que trabajó con "la cultura brasileña" como mulata (bailarina de ritmos brasileños) durante 10 años bailando samba y usando trajes típicos del carnaval brasileño hechos por ella misma en diferentes eventos festivos en Santiago. Como el baile era exótico y sensual, Tania comenta que era responsabilidad de cada bailarina darse el respeto - en el sentido de cuidar sus movimientos para que su baile no pareciera vulgar- para evitar el asedio sexual de hombres del público. Para protegerse, Tania utilizó la siguiente estrategia:

Yo cuando entraba en el escenario, entraba para representar la cultura, no entraba con vulgaridad [...] Estaba con muy poca ropa, pero me comportaba [...] Cuando entraba en el escenario, era una artista [...]. Y no era una exhibición, era un evento, era una expresión: "aquí está la cultura brasileña", eso, esa era la onda (Tania, Entrevista 1:192;194).

Con el tiempo, Tania se cambió de rubro laboral: pagó un curso de estética en manicure y empezó a trabajar con el "arte de las uñas" (Tania, Entrevista 1:52). Actualmente, gerencia y trabaja en su propio salón de belleza que arrienda en sociedad con compañeras de su formación estética. Como microempresaria, Tania relata no dejar atrás los elementos que para ella representan la cultura brasileña: los colores verde y amarillo, la bandera, la música. En cada uno de nuestros encuentros se vistió con los colores de la bandera de Brasil, su salón de belleza también estaba decorado con la bandera, y las fotos elegidas retrataron un pasado en que trabajaba con esos elementos.

Aunque Tania afirme que esa expresividad hace parte de "cualquier brasileño", porque "un brasileño de verdad es nacionalista, ama su país, ama su bandera" (Tania, Entrevista 1:148), no la encontramos con la misma intensidad en casos de otras/os participantes, como en el relato de Vida. Una de las diferencias en términos de categorías sociales entre las participantes se encuentra en su situación socioeconómica antes y después de la migración, lo que nos podría dar pistas de la relevancia de la clase social en la configuración de escenarios específicos para la producción de identidades narrativas.

\section{Brasilidades en Santiago: entre estigma y agencia}

En el escenario internacional, una serie de imágenes son atribuidas a la brasilidad, producidas en torno a un tropicalismo brasileño: características de comportamiento - ser alegre, cordial, simpático y afectuoso, la caradurez (Padilla, Oliveira Fernandes y Gomes, 2017), la hipersexualización (Gomes, 2018), el uso de ropas llamativas, los modales más expresivos (Guizardi, 2013); características fenotípicas -el color de piel, que por veces se espera ser moreno y negro, los rasgos físicos, con trazos mestizos o afrodescendientes, los cuerpos voluptuosos (Guizardi, 2013); y características culturales- la música brasileña (samba, forró, sertanejo), los bailes típicos, los colores verde y amarillo (de la bandera de Brasil), el fútbol, el Carnaval, la vinculación con el universo laboral de la estética, entre otros (Ballerini, 2018; Guizardi, 2013).

En Chile, las imágenes sobre qué significa ser de nacionalidad brasileña se expresan en el relato de los/las participantes y, en general, se vinculan a la buena recepción de brasileños/as en el país, a la idea de Brasil como un país tropical y paradisíaco y a una imagen de los/las brasileños/as como alegres, de fácil trato y siempre disponibles para celebrar -algo parecido a cómo la inmigración brasileña es vista en Argentina (Frigerio, 2005; Gallero, 2016). Estas y otras características se constituyen, según nuestra interpretación, como una categoría sociocultural con la cual los/las brasileños/as en Santiago tienen que relacionarse y negociar formas de ser y vivir en la sociedad de destino, aunque las características culturales regionales de origen y su manera de actuar 
en el mundo sean diferentes de dicha brasilidad. Por lo tanto, incorporamos la etnia-nacionalidad con las relaciones de género y raciales en la sociedad receptora para entender la experiencia de producción identitaria de ese grupo migrante.

Según Ballerini (2018), aunque sean construidas socio-históricamente, las categorías son vividas en los cuerpos de los sujetos, y esa corporalidad interseccional es aún más evidente en grupos racializados y etnicizados, como los/las migrantes brasileños/as (Padilla, Oliveira Fernandes y Gomes, 2017). Sin embargo, el grupo no es homogéneo y las diferentes posiciones sociales en la trama de las matrices de dominación ofrecen diferentes posibilidades de existir en la vida social. El género fue el primer gran marcador social de desigualdades que analizamos. Si bien tradicionalmente el proceso migratorio internacional produce cambios en las relaciones de género en los espacios interpersonales, principalmente de la vida privada y familiar para las mujeres (Nawyn, 2010), observamos que en el caso brasileño en Santiago las mujeres han ganado espacios en la vida pública de la sociedad de destino -conquista de trabajos cualificados de mejor remuneración que en Brasil, emprendimiento de nuevos negocios y proyectos, trabajar con lo que les gusta hacer y ganar visibilidad con ello- distanciándose del mercado de cuidado a través del cual mujeres de otros colectivos migrantes sudamericanos usualmente se insertan en el país (Stefoni, 2009). En algunos casos, las mujeres brasileñas en Santiago habitan nichos laborales similares a los que ocupan en el norte global, como el mercado de la belleza y estética (Guizardi, 2013; Malheiros y Padilla, 2014). Por otro lado, participantes hombres han podido reconocer el emprendimiento de proyectos migratorios por amor y han buscado estar más presentes en la vida familiar, produciendo identidades en el intersticio entre la vida afectiva y profesional.

Además, las mujeres se beneficiaron con la migración en términos de agencia subjetiva, aun cuando migran a través de estrategias aparentemente no tan liberadoras, como acompañar a sus parejas, pues tuvieron en el proceso migratorio la posibilidad de reinventar sus narrativas, de elegir qué se podría ser y a qué grupos pertenecer. Eso les ha conferido una sensación de mayor libertad y capacidad de agenciamiento, algo bastante similar a lo relatado por mujeres mexicanas calificadas en Santiago (Gissi Barbieri y Martínez Ruiz, 2018).

Sin embargo, todavía hay un conjunto de vivencias socioculturales pautadas desde el género que producen importantes limitaciones para las brasileñas en Santiago. La violencia de género, física y psicológica en el ámbito público y privado, relatada por las mujeres estudiadas, se entrecruza a la etnia-nacionalidad tropical-brasileña, produciendo la sexualización, la erotización y la exotización de sus cuerpos. Este fenómeno ha sido ampliamente estudiado en países del norte global (Ballerini, 2018; Gomes, 2018; Guizardi, 2013; Malheiros y Padilla, 2014; Padilla, 2007b; Padilla, Oliveira Fernandes y Gomes, 2017; Piscitelli, 1996; 2007; 2008; 2011) y todavía se encuentra muy presente en la experiencia de brasileñas emigrantes, en que las sociedades hospederas interactúan con ellas a partir de estigmas de salvajismo sexual y prostitución, cuerpos exóticos que deben ser controlados y sometidos (Guizardi, 2013).

En los países europeos, las brasileñas serían todas racializadas, independiente de su color de piel (Padilla, 2007b), vistas como mulatas o morenas pobres del sur global que inmigran para trabajar en el mercado del sexo o matrimonial (Piscitelli, 1996; 2007; 2008). Son mujeres de color, así como otras mujeres latinoamericanas, indígenas, asiáticas y africanas, que son marginalizadas en un sistema de poder eurocéntrico y masculino (Lugones, 2008). Especialmente en el caso de las mujeres brasileñas en Portugal, se agrega a la matriz de opresión la relación entre ex colonos y ex metrópoli (Gomes, 2013; 2018). Incluso en las casas de acogida de migrantes y en los documentos oficiales del Estado portugués sobre la migración, las brasileñas son relacionadas al sexo y a la prostitución, como si ello fuera parte de su naturaleza tropical, lo que justificaría la discriminación sufrida por ellas en el país. Lo anterior refuerza la colonialidad del género y "la percepción de todas las brasileñas como cuerpo colonial disponible e hipersexualizado" (Gomes, 2018:433).

La inmigración brasileña hacia Santiago, no obstante, se diferencia de esos estudios internacionales en tres puntos. Primero, los/las participantes relataron que la migración brasileña en general no es vista desde la pobreza, sino que es interpretada como turismo, una visita que trae dinero al país. Segundo, si bien la sociedad receptora trata a brasileños/as desde estereotipos culturales poco flexibles (tropicalismo brasileño), la buena recepción e interés por elementos 
culturales brasileños por parte de chilenos/as hace que la discriminación sea mitigada si comparada con otros colectivos migrantes, principalmente en la experiencia de afrodescendientes. Tercero, si en el norte global las brasileñas pueden ser racializadas como no-blancas y vinculadas al mercado del sexo, en Santiago las brasileñas blancas son hipersexualizadas, pero no necesariamente vinculadas a la prostitución ni racializadas/mulatizadas. Estos estigmas, empero, sí son relatados por las mujeres brasileñas afrodescendientes.

Sobre este último punto, es interesante que entendamos la importancia de la categoría raza en la sociedad chilena. La inmigración internacional en Chile ha sido percibida como invasión por parte de sus ciudadanos en los últimos 20 años: una migración mayoritariamente latinoamericana, no-blanca y de bajos recursos amenazaría la idea de nación basada en una utopía de "raza chilena" europeizada (Sirlopú y Van-Oudenhoven, 2013; Tijoux, 2012; 2016). Así, cuanto más lejos del patrón fenotípico-cultural chileno utópico, más el inmigrante puede experimentar el racismo mientras intenta insertarse socialmente (Tijoux, 2016).

La actitud chilena frente a la inmigración latinoamericana cambia según el grupo étnico al que se relaciona (Sirlopú y Van-Oudenhoven, 2013; Thayer, Córdoba y Ávalos, 2013) y la clase socioeconómica a la que pertenece, produciendo una racialización diferencial (Brah, 2011): si el colectivo migrante no es blanco, de clase baja y con poca escolaridad, el resultado puede ser una actitud agresiva y de hostilidad cotidiana por la sociedad receptora (Cárdenas, Gómez, Méndez y Yañez, 2011). Esa situación se agudizó con la llegada de haitianos y colombianos en el país, el tercer y cuarto colectivo de mayor tamaño en Chile, respectivamente (INE, 2020). Con rasgos afrodescendientes, dichos grupos reciben discriminación y rechazo: son caracterizados como ladrones de empleo, en el caso de haitianos/as (Rojas Pedemonte, Amode y Vasquez Rencoret, 2015), narcotraficantes y prostitutas, en el caso de los/las colombianos/as (Labbé, Allendes, Sanhueza y O'Ryan, 2020).

En este contexto, la población brasileña blanca tiene en Santiago la posibilidad de no ser objeto de racialización (aunque sí puede ser etnicizada por su brasilidad) y, para evitar la xenofobia y la hipersexualización (en el caso de las mujeres), pueden intentar esconder su acento brasileño como estrategia para pasar desapercibidas, práctica conocida entre migrantes brasileños/as en Portugal (Padilla, Oliveira Fernandes y Gomes, 2017).

Esa condición no es la misma para brasileños/as afrodescendientes, que pueden ser discriminados en el primer contacto con la sociedad santiaguina. Considerando la inseparabilidad del género y la raza, principalmente en el caso brasileño (Piscitelli, 1996) y su importancia como determinante de desigualdades, las mujeres afrobrasileñas serían un "otro" de mayor complejidad: por ser migrantes, mujeres y negras (Padovani, 2017). Sin poder pasar desapercibidas en su cotidiano, tendrían que aferrarse más fuertemente al "recurso" de la etnización (brasilidad) para además de lidiar con el racismo, mitigar la violencia sobre el hecho específico de ser mujer-negra. La interacción género-raza-nacionalidad en este caso hace de la posición social de mujerafrobrasileña en Santiago un eje en las matrices de dominación en que las negociaciones identitarias se dan constantemente entre agencia y sujeción a los estigmas en torno a sus cuerpos.

$\mathrm{Si}$ es en los juegos de mismidad y diferencia que las identidades son producidas (Ricoeur, 1996), las identidades narrativas de esas mujeres, al encarnar el lugar de la diferencia ("otro"), son formadas bajo la urgencia de escapar de la violencia cotidiana por el estigma de ser mujer-negra, que las empuja más fuertemente a un lado de las relaciones entre marcos socioculturales brasileños y chilenos en Santiago: se tornan las brasileñas por excelencia, hacen uso del acento brasileño marcado en su español, de los colores de Brasil, de los bailes brasileños, de la sensualidad y exotización de los cuerpos.

Un ejemplo es el relato de Tania, quién trabajó de mulata (bailarina de samba) por 10 años. La mulata es solo cuerpo (Corrêa, 1996:40), y ocupa en el imaginario popular e internacional el lugar contradictorio de lo deseable/atractivo (caliente, afectuoso, sensual, rico), y de lo indeseable/rechazo (pecaminoso, la perdición, lo inmoral) (Corrêa, 1996). Trabajar de mulata sería hacer performance de esas contradicciones, encarnar las imágenes de brasilidad del discurso hegemónico y jugar con el deseo del espectador, que en el caso de la migración brasileña sería la sociedad receptora. Cabe a la mulata la responsabilidad de "darse el respeto", de cuidar sus 
movimientos corporales y no ser excesivamente sensual, para no ser atacada por ese deseo, como dijo Tania.

Sin embargo, la fuerza de resistencia de esas mujeres a las matrices de dominación les ha conferido mayores niveles de agencia subjetiva en la sociedad de llegada, algo que también permea sus narrativas identitarias. Tania usó su trabajo de mulata como estrategia para adquirir las condiciones económicas necesarias y salir de la dependencia de su exmarido. Aunque se trate de un trabajo que erotiza y exotiza las mujeres brasileñas, trabajar de bailarina posibilitó a Tania usar su cuerpo como herramienta artística, encarnando las características culturales brasileñas como performance, tal como otras brasileñas emigrantes lo han hecho para conseguir mejor independencia económica y calidad de vida (Gomes, 2013). También a través del baile, construyó una red de amistades, empezó a profesionalizarse y se tornó emprendedora de su salón de belleza. Y cuando su sueño de volver a Brasil no se puede concretar, utiliza de la brasilidad estereotipada en Santiago para construir su propio Brasil donde se encuentra, así como para diferenciarse de otros grupos migrantes más discriminados.

Finamente, la condición socioeconómica se mostró importante en cuanto a marcador de desigualdades entre las dos mujeres afrobrasileñas que destacamos. Tania, afrodescendiente de escasos recursos, no ha podido realizar su sueño de estudiar una carrera universitaria, ha pasado por el mayor umbral de violencia relatado, y actualmente vive y transita en espacios asociados a migrantes afrodescendientes pobres, por lo que la necesidad de usar de la brasilidad como estrategia performativa se hace más expresiva en su cotidiano en Santiago y en su narración sobre sí. Vida, en cambio, contó con herramientas socioeconómicas para enfrentar los estigmas de su posición social, pudo estudiar en buenos colegios en Brasil, aprender inglés e ir a la universidad. Todo eso, si bien la condujo a producir su identidad por el sesgo profesional, hizo que su migración a Chile tuviese un carácter de agencia subjetiva más acentuado: Vida pudo decidir hacer de Santiago el lugar para invertir en sus deseos de construir familia y de dedicarse a las artes, de modo que su relación con la brasilidad parece ser mucho menos estereotipada si comparada a Tania.

\section{Consideraciones finales}

En este artículo, buscamos comprender los procesos identitarios subjetivos de inmigrantes brasileños/as en Santiago, explorando la importancia del cruce de las categorías de diferenciación como definidores de experiencias e identidades. Recurrimos a un análisis "BiográficoInterseccional", que nos permitió identificar, por un lado, dos grandes marcadores de desigualdades: el género-nacionalidad y el género-raza-nacionalidad, y por el otro, evidenciar cómo una condición socioeconómica favorable (recursos financieros y mayores niveles de educación formal) ofrecen espacios menos rígidos de producción identitaria y mayores capacidades de agenciamiento. También mostramos cómo la corporalidad se evidencia de manera transversal en las categorías de diferenciación de las brasileñas en Santiago, pero que a su vez permite crear un territorio de resistencias y subversión, especialmente en el relato de las mujeres afrodescendientes.

Asimismo, subrayamos cómo las identidades narrativas de los/las participantes fueron negociadas y producidas entre momentos de agencia y sujeción con su entorno y con el imaginario internacional sobre lo que se considera brasilidad, donde el cuerpo pudo ser el espacio mismo de esas negociaciones. Dependiendo de la posición social de cada participante, fue posible tener más flexibilidad y agencia en la enunciación de la propia historia. En el caso específico de ser brasileño/a en Santiago, estar posicionado/a en el cruce de ciertas categorías más oprimidas históricamente (ser mujer y afrodescendiente) puede significar tener que vincularse de manera más cercana a los estereotipos de brasilidad en el espacio entre marcos socioculturales de las sociedades de origen y de destino, derivando en identidades intersticiales más estereotipadas. Sin embargo, incluso en esas situaciones, es posible ser agente en la producción de las narrativas de sí mismo.

Finalmente, destacamos cómo, en Santiago, el género no es necesariamente racializado pues ni todas las mujeres brasileñas son vistas como mulatas y vinculadas a la prostitución o a la disponibilidad sexual, como sí sucede en Portugal. Hipotetizamos que ello se debe a que otras mujeres latinoamericanas ocupen ese lugar racializado-sexualizado inferiorizado, mientras que los/las brasileños/as ocupan un lugar mejor posicionado en dicha jerarquía social. Incluso en el caso 
de las afrobrasileñas, la etnicidad les permite diferenciarse de otras afrolatinas "peor evaluadas". Lo anterior indicaría la importancia de repensar el proceso de racialización y etnización en cada contexto donde se vive la experiencia migratoria y la necesidad de plantear investigaciones sobre los sistemas de "racialización diferencial" (Brah, 2011:217) entre grupos del sur global.

\section{Referencias bibliográficas}

ALMEIDA, Silvio. Racismo estrutural. São Paulo-SP, Editora Pólen Livros, 2019.

ANTHIAS, Floya. Transnational mobilities, migration research and intersectionality: towards a translocational frame. Nordic Journal of Migration Research, v. 2, n. 2, 2012, Helsinki-Noruega, pp.102-110 [http://archive.sciendo.com/NJMR/njmr.2012.2.issue-2/v10202-011-0032-y/v10202-011-0032-y.pdf acceso en 22 de agosto de 2020].

BALLERINI, Damiana. A "imagem" das mulheres brasileiras no exterior: corpos, meios de comunicação e discursos. Anales del VII Seminário Corpo, Genero e Sexualidade da Universidade Federal do Rio Grande (FURG), seteptiembre de 2018 [https://7seminario.furg.br/images/arquivo/336.pdf - acceso em 15 de julio de 2020].

BEDREGAL, Paula et alii. La investigación cualitativa: un aporte para mejorar los servicios de salud. Rev. méd. Chile, v.145, n. $\quad 3, \quad$ 2017, [https://scielo.conicyt.cl/scielo.php?script=sci_arttext\&pid $=$ S0034$98872017000300012 \& \operatorname{lng}=e s \& n r m=$ iso - acceso en 15 de junio de 2020]. doi:http://dx.doi.org/10.4067/S0034-98872017000300012.

BENJAMIN, Jessica. The bonds of love: psychoanalysis, feminism, and the problem of domination. New York-NY, Pantheon Books, 1988.

BHABHA, Homi K. O lugar da cultura. Belo Horizonte-MG, Editora UFMG, 1998 [1994].

BRAH, Avtar. Cartografías de la diáspora. Identidades en cuestión. Madrid, Traficantes de Sueños, 2011 [1996].

BRAH, Avtar; PHOENIX, Ann. Ain't I a Woman? Revisiting Intersectionality. Journal of International Women's Studies, v. 5, n. 3, 2004, pp.75-86 [http://vc.bridgew.edu/jiws/vol5/iss3/8 - acceso en 02 de octubre de 2021].

BÜRKNER, Hans-Joachim. Intersectionality: how gender studies might inspire the analysis of social inequality among migrants. Population, Space and Place (18), 2012, pp.181-195 [https://doi.org/10.1002/psp.664 acceso en 22 de agosto de 2020].

CANCLINI, Néstor Garía. Culturas Hibridas: Estrategias para entrar y salir de la modernidad. Buenos Aires, Editora Paidós, 2008 [1990].

CÁRDENAS, Manuel et alii. Reporte de los niveles de prejuício sutil y manifiesto hacia los inmigrantes bolivianos y análisis de su relación con variables psicosociales. Psicoperspectivas: indivíduo y sociedad, v. 10 , n. $1, \quad 2011$, pp.125-143 [https://scielo.conicyt.cl/scielo.php?script=sci arttext\&pid=S0718$69242011000100007 \& \operatorname{lng}=e s \& n r m=$ iso $\quad-$ acceso en 12 de agosto de 2020]. doi:10.5027/psicoperspectivas-Vol10-Issue1-fulltext-134

CORRÊA, Mariza. Sobre a invencao da mulata. cadernos pagu (6-7), Núcleo de Estudos de GêneroPagu/Unicamp, 1996, pp.35-50 [https://periodicos.sbu.unicamp.br/ojs/index.php/cadpagu/article/view/1860 - acceso en 20 de junio de 2020].

CRENSHAW, Kimberle. Mapping the Margins: Intersectionality, Identity Politics, and Violence against Women of Color. Stanford Law Review, v. 43, n. 6, 1991, pp.1241-1299 [http://www.jstor.org/stable/1229039 acceso en 28 de marzo de 2020].

DE GAUlEJAC, Vicent. Historia de Vida y Sociología Clínica. Proposiciones (29), Santiago de Chile, Ediciones SUR, 1996, pp.1-13 [http://www.sitiosur.cl/r.php?id=750 - acceso en 22 de junio de 2020].

DOMÍNGUEZ, Màrius; CONTRERAS, Paola. Agencia femenina en los procesos migratorios internacionales: Una aproximación epistemológica. EMPIRIA: Revista de Metodología de Ciencias Sociales (37), mayo- 
agosto, 2017, pp.75-99 [https://doi.org/10.5944/empiria.37.2017.18977 - acceso en 20 de septiembre de 2020].

DOÑA-REVECO, Cristián. Amid Record Numbers of Arrivals, Chile Turns Rightward on Immigration. Migration Information Source, Washington DC, 17 de enero de 2018. [https://www.migrationpolicy.org/article/amid-record-numbers-arrivals-chile-turns-rightward-immigration acceso en 25 de agosto de 2020].

FRIGERIO, Alejandro. Migrantes exóticos: Los brasileños en Buenos Aires. RUNA, Archivo Para Las Ciencias Del Hombre, v. 25, n. 1, 2005, pp.97-121 [https://doi.org/10.34096/runa.v25i1.1257 - acceso en 25 de agosto de 2020].

GALLERO, María Cecília. Las particularidades de la inmigración brasileña en la Argentina. Cadernos $\begin{array}{llllll}\text { OBMigra, } & \text { v. } & 2, & \mathrm{n} . & 1, & 2016,\end{array}$ [https://ri.conicet.gov.ar/bitstream/handle/11336/44974/CONICET_Digital_Nro.27865d8a-d024-43aea8d2-15ce6df80dd2_A.pdf?sequence $=2 \&$ isAllowed $=y-$ acceso en 12 de agosto de 2020].

GIACOMINI, Sonia Maria. Aprendendo a ser mulata: um estudo sobre a identidade da mulata profissional. In: DE OLIVEIRA COSTA, Albertina; BRUSCHINI, Cristina (ed.). Entre a virtude e o pecado. Rio de JaneiroRJ, Editora Rosa dos Tempos, 1991, pp.213-246.

GISSI-BARBIERI, Nicolás; MARTINEZ-RUIZ, Susana. Trayectorias de género en la migración sur-sur de mujeres mexicanas calificadas en Santiago de Chile. Si Somos Americanos, v.18, n. 1, 2018, pp.83-118 [https://scielo.conicyt.cl/scielo.php?script=sci arttext\&pid=S0719$09482018000100083 \& \operatorname{lng}=e s \& n r m=$ iso $\quad$ - acceso en 12 de agosto de 2020] doi:http://dx.doi.org/10.4067/S0719-09482018000100083.

GOFFMAN, Erving. Estigma: la identidad deteriorada. Buenos Ares, Amorrortu Editores, 2006 [1963].

GOMES, Mariana Selister. Gênero, Colonialidade e Migrações: uma análise de discursos institucionais sobre a "Brasileira Imigrante" em Portugal. Política e Sociedade, v. 17, n. 38, 2018, pp.404-439 [https://doi.org/10.5007/2175-7984.2018v17n38p404 - acceso en 02 de octubre de 2021].

GOMES, Mariana Selister. O imaginário social < Mulher Brasileira > em Portugal: uma análise da construção de saberes, das relações de poder e dos modos de subjetivação. DADOS: Revista de Ciências Sociais, v. 56, n. 4, Rio de Janeiro-RJ, 2013, pp.867-900 [https://www.redalyc.org/pdf/218/21829905005.pdf acceso en 12 de julio de 2020].

GÓMEZ, Ricardo. Raíces y ramas al viento: experiencias colombianas de migración y prácticas de información. Revista CS (22), pp.33-53 [https://www.icesi.edu.co/revistas/index.php/revista_cs/article/view/2267 - acceso en 7 de agosto de 2020].

GÓMEZ, Ricardo. Vulnerabilidad y prácticas de información: experiencias de migrantes latinos (indocumentados) en EE.UU. Revista CS (20), 2016, pp.93-121 [https://doi.org/10.18046/recs.i20.2211acceso en 7 de agosto de 2020].

GUIZARDI, Menara Lube. Estereotipos, identidades, y nichos económicos de las migrantes brasileñas en Madrid. Rev. Estud. Fem., v. 21, n. 1, 2013, pp.167-190 [http://www.scielo.br/scielo.php?script=sci_arttext\&pid $=$ S0104-026X2013000100009\&lng $=$ en\&nrm $=$ iso - acceso en 12 de agosto de 2020].

HALL, Stuart. Introducción: ¿Quién necesita identidad? In: HALL, Stuart; DU GAY, Paul. Cuestiones de Identidad Cultural. Buenos Aires, Amorrortu, 2003, pp.13-39.

HILL-COLLINS, Patricia Hill. Black feminist thought: knowledge, consciousness, and the politics of empowerment. New York-NY, Routledge, 2002 [2000].

INSTITUTO Nacional de Estadísticas de Chile [INE]. Estimación de personas extranjeras residentes habituales en Chile al 31 de diciembre 2019: Informe Técnico. Santiago de Chile, Departamento de Extranjería y Migración, 2020a. [https://www.ine.cl/docs/default-source/demografia-y-migracion/publicaciones-yanuarios/migraci\%C3\%B3n-internacional/estimaci\%C3\%B3n-poblaci\%C3\%B3n-extranjera-en-chile2018/estimaci\%C3\%B3n-poblaci\%C3\%B3n-extranjera-en-chile-2019metodolog\%C3\%ADa.pdf?sfursn $=5$ b145256 6 - acceso en 22 de junio de 2020].

INSTITUTO Nacional de Estadísticas de Chile [INE]. Estimación de personas extranjeras residentes habituales en Chile al 31 de diciembre 2019: Informe Técnico, desagregación regional y comunal. Santiago de Chile, 
Departamento de Extranjería $\quad$ y $\quad$ Migración, $2020 \mathrm{~b}$. [https://www.extranjeria.gob.cl/media/2020/06/estimaci\%C3\%B3n-poblaci\%C3\%B3n-extranjera-en-chile2019-regiones-y-comunas-metodolog\%C3\%ADa.pdf - acceso en 25 de agosto de 2020].

JOSEPH, Tiffany D. Race on the Move: Brazilian Migrants and the Global Reconstruction of Race. StanfordCA, Stanford University Press, 2013.

JULIANO, Dolores. Cultura y exclusión. Polémica teórica. Quaderns de l'Institut Català d'Antropologia, n. 19, 2003, pp.55-67 [https://raco.cat/index.php/QuadernsICA/article/view/95560 - acceso en 20 de octubre de 2021].

LABBÉ, Juan Fernández; ALLENDES, Vivián Díaz; SANHUEZA; Tatiana Aguirre y O'RYAN, Valentina Cortínez. Mujeres colombianas en Chile: discursos y experiencia migratoria desde la interseccionalidad. Revista Colombiana de Sociología, v. 43, n. 1, 2020, pp.17-36 [https://revistas.unal.edu.co/index.php/recs/article/view/79075 - acceso en 12 de agosto de 2020]. doi:https://doi.org/10.15446/rcs.v43n1.79075

LEGRAND, Michel. La contra-transferencia del investigador en los relatos de vida. Proposiciones (29), Santiago de Chile, Ediciones SUR, 1996, pp.1-7 [http://www.sitiosur.cl/r.php?id=435 - acceso en 22 de junio de 2020].

LUGONES, María. Colonialidad y género. Tabula Rasa, n. 9, julio-diciembre, 2008, pp.73-101 [https://www.redalyc.org/articulo.oa?id=39600906 - acceso en 03 de octubre de 2021].

MALHEIROS, Jorge; PADILLA, Beatriz. Can stigma become a resource? The mobilisation of aestheticcorporal capital by female immigrant entrepreneurs from Brazil. Identities: Global Studies in Culture and Power (22), 2014, pp.687-705 [http://dx.doi.org/10.1080/1070289X.2014.950970 - acceso en 12 de julio de 2020].

MAGLIANO, María José. Interseccionalidad y migraciones: potencialidades y desafíos. Revista Estudos Feministas, v. 23, n. 3, Florianópolis-SC, 2015, pp.691-712 [http://dx.doi.org/10.1590/0104026X2015v23n3p691 - acceso en 2 de junio de 2020].

MARTÍNEZ-GUZMÁN, Antar; MONTENEGRO, Marisela. La producción de narrativas como herramienta de investigación y acción sobre el dispositivo de sexo/género: Construyendo nuevos relatos. Quaderns de Psicologia, v. 16, n. 1, 2014, pp.111-125 [https://www.quadernsdepsicologia.cat/article/view/1206 - acceso en 17 de junio de 2020]. doi: https://doi.org/10.5565/rev/qpsicologia.1206

MCCLINTOCK, Anne. Couro imperial. Raça, gênero e sexualidade no embate colonial. Campinas, SP, Editora da Unicamp, 2010 [1995].

NAWYN, Stephanie J. Gender and Migration: integrating feminist theory into migration studies. Sociology Compass, v. 4, n. 9, 2010, pp.749-765 [https://doi.org/10.1111/j.1751-9020.2010.00318.x - acceso en 12 de junio de 2020].

OLIVEIRA-ASSIS, Gláucia de. Gender and migration from invisibility to agency: The routes of Brazilian women from transnational towns to the United States. Women's Studies International Forum (46), 2014, pp.33-44 [https://doi.org/10.1016/j.wsif.2014.01.003 - acceso en 12 de junio de 2020].

ORTNER, Sherry. Antropología y teoría social: Cultura, poder y agencia. San Martín, Argentina, UNSAM EDITA, 2016 [2006].

PADILLA, Beatriz. A imigrante brasileira em Portugal: considerando o género na análise. In: MALHEIROS, Jorge Macaísta (org.). Imigração brasileira em Portugal. Lisboa, Alto Comissariado para a Imigração e Diálogo Intercultural (ACIDI), 2007a, pp.113-134.

PADILLA, Beatriz. Brasileras en Portugal: de la transformación de las diversas identidades a la exotización. Amérique Latine Histoire et Mémoire. Les Cahiers ALHIM, (14), 2007b [http://journals.openedition.org/alhim/2022 - acceso en 30 de agosto de 2020].

PADILLA, Beatriz; GOMES, Mariana Selister. Empoderamento, interseccionalidade e ciberativismo: Uma análise do "Manifesto contra o preconceito às mulheres brasileiras em Portugal". TOMO (28), enero-junio, 2016, pp.169-201 [https://doi.org/10.21669/tomo.v0i0.5425 - acceso en 20 de agosto de 2020].

PADILLA, Beatriz; GOMES, Mariana Selister. Racismo contra as mulheres brasileiras em Portugal? Algumas reflexões. VII Congresso Portugues de Sociologia, Porto-PT, Junio de 2012, pp.1-14 
[http://associacaoportuguesasociologia.pt/vii_congresso/papers/finais/PAP0271_ed.pdf - acceso em 30 de agosto de 2020].

PADILLA, Beatriz; OLIVEIRA FERNANDES, Gleiciani Maria de; GOMES, Mariana. Ser brasileña en Portugal: inmigración, género y colonialidad. In: MAGLIANO, María José; MALLIMACI, Ana Inés (comp.). Las mujeres latinoamericanas y sus migraciones. Córdoba, Editorial Universitaria Villa, 2017, pp.141-166.

PADOVANI, Natália Corazza. É possível fazer Ciências Sociais sem uma análise crítica das categorias de diferenciação? Uma proposição feminista. Cadernos de Estudos Sociais e Políticos, v. 7, n. 12, Rio de Janeiro-RJ, 2017, pp.6-30 [https://doi.org/10.12957/cesp.2017.37720 - acceso en 07 de agosto de 2020].

PESSAR, Patricia; MAHLER, Sarah J. Transnational Migration: Bringing Gender in. The International Migration Review, v. 37, n. 3, 2003, pp.812-846 [https://www.jstor.org/stable/30037758 - acceso en 12 de julio de 2020].

PISCITELLI, Adriana. ¿Actuar la brasileñidad? Tránsitos a partir del mercado del sexo Etnográfica, v. 15, n. 1, 2011, pp.5-29 [http://journals.openedition.org/etnografica/765 - acceso en 15 de julio de 2020] doi: 10.4000/etnografica.765

PISCITELLI, Adriana. Interseccionalidades, categorias de articulação e experiências de migrantes brasileiras.Sociedade e Cultura, v. 11, n. 2, 2008, pp.263-274 [https://doi.org/10.5216/sec.v11i2.5247 acceso en 07 de agosto de 2020].

PISCITELLI, Adriana. Sexo tropical em um país europeu: migração de brasileiras para a Itália no marco do "turismo sexual" internacional. Rev. Estud. Fem., v. 15, n. 3 2007, pp.717-744 [http://dx.doi.org/10.1590/S0104-026X2007000300014 - acceso en 07 de agosto de 2020].

PISCITELLI, Adriana. "Sexo tropical": Comentários sobre gênero e "raça" em alguns textos da mídia brasileira. cadernos pagu (6/7), Campinas,SP, Núcleo de Estudos de Gênero-Pagu/Unicamp, 1996, pp.933 [https://periodicos.sbu.unicamp.br/ojs/index.php/cadpagu/article/view/1859 - acceso en 07 de agosto de 2020].

RHEAUME, Jacques. La aproximación clínica en las Ciencias Humanas. Proposiciones (29), Santiago de Chile, Ediciones SUR, 1996, pp.1-6 [http://www.sitiosur.cl/r.php?id=538 - acesso em 22 de junho de 2020].

RICOEUR, Paul. Sí mismo como otro. Madrid, Editora Siglo XXI, 2006 [1996].

ROJAS-PEDEMONTE, Nicolás; AMODE, Nassila; VASQUEZ-RENCORET, Jorge. Racismo y matrices de "inclusión" de la migración haitiana en Chile: elementos conceptuales y contextuales para la discusión. Polis, $\quad$ v. $14, \quad$ n. $\quad 42, \quad$ Santiago, $2015, \quad$ pp.217-245 [https://scielo.conicyt.cl/scielo.php?script=sci_arttext\&pid=S0718$65682015000300011 \& \operatorname{lng}=e s \& n r m=$ iso - acceso en 05 de mayo de 2020]. doi:http://dx.doi.org/10.4067/S0718-65682015000300011.

SHARIM, Dariela. La identidad de género en tiempos de cambio: una aproximación desde los Relatos de Vida. Psykhe, ano 14, n. 2, Santiago de Chile, 2005, pp.19-32 [http://www.psykhe.cl/index.php/psykhe/article/view/285 - acceso em 12 de junio de 2020].

SIRLOPÚ, David; VAN-OUDENHOVEN, Jan Pieter. Is multiculturalism a viable path in Chile? Intergroup and acculturative perspectives on Chilean society and Peruvian immigrants. International Journal of $\begin{array}{llllll}\text { Intercultural Relations, } & \text { v. } 37, \quad \mathrm{n} . & 6, & 2013, & \text { pp.739-749 }\end{array}$ [https:/www.sciencedirect.com/science/article/abs/pii/S0147176713001132?via\%3Dihub - acceso en 12 de agosto de 2020]. doi:10.1016/j.ijintrel.2013.09.011

SOTO-ALVARADO, Sylvia. Los estudios sobre inmigración internacional en Chile en el siglo XXI: Un estado de la cuestión. Revista Bibliográfica de Geografía y Ciencias Sociales (Biblio3W), ano 25, n. 1304, Barcelona, Universidad de Barcelona, agosto de 2020, pp.1-23 [https://revistes.ub.edu/index.php/b3w/article/view/31496 - acesso em 25 de agosto de 2020].

STEFONI, Carolina. Migración, género y servicio doméstico: Mujeres peruanas en Chile. In: VALENZUELA, María Elena; MORA, Claudia (ed.). Trabajo doméstico: un largo camino hacia el trabajo decente. Santiago de Chile, Oficina Internacional del Trabajo [OIT], 2009, pp.191-232. 
STEFONI, Carolina; BONHOMME, Macarena. Una vida en Chile y seguir siendo extranjeros. Si Somos Americanos: Revista de Estudios Transfronterizos, v. 14, n. 2, 2014, pp.81-101 [http://dx.doi.org/10.4067/S0719-09482014000200004 - acesso em 12 de abril de 2020].

STEFONI, Carolina; FERNÁNDEZ, Rosario. Mujeres inmigrantes en el trabajo doméstico: entre el servilismo y los derechos. In: STEFONI, Carolina (ed.). Mujeres Inmigrantes en Chile: ¿Mano de obra o trabajadoras con derechos? Santiago de Chile, Ediciones Universidad Alberto Hurtado, 2011.

STEFONI, Carolina; STANG, Fernanda. La Construcción del Campo de Estudio de las Migraciones en Chile: Notas de un Ejercicio Reflexivo y Autocrítico. Íconos. Revista de Ciencias Sociales, v. 5, n. 58, Quito, FLACSO Equador, 2017, pp.109-129 [https://doi.org/10.17141/iconos.58.2017.2477 - acesso em 12 de abril de 2020].

THAYER, Luis Eduardo; CORDOVA, María Gabriela; AVALOS, Betania. Los límites del reconocimiento: migrantes latinoamericanos en la Región Metropolitana de Santiago de Chile. Perf. latinoam., v. 21, n. 42, 2013, pp.163-191 [http://www.scielo.org.mx/scielo.php?script=sci_arttext\&pid=S0188-

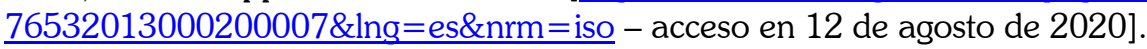

TIJOUX, María Emília. Negando al 'otro': el constante sufrimiento de los inmigrantes peruanos en Chile. In: STEFONI, Carolina. Mujeres Inmigrantes en Chile: ¿mano de obra o trabajadoras con derechos? Santiago de Chile, Ediciones Universidad Alberto Hurtado, 2012, pp.15-42.

TIJOUX, María Emília. Racismo en Chile: La Piel Como Marca de la Inmigración. Santiago de Chile, Editora Universitaria, 2016.

TOGNI, Paula Christofoletti. A Europa é o Cacém: mobilidades, gênero e sexualidade nos deslocamentos de jovens brasileiros para Portugal. Tese (Doutorado em Antropologia), ISCTE-IUL, Lisboa, 2014 [http://hdl.handle.net/10071/8679 - acceso en 02 de octubre de 2021].

YEFIMOVA, Katya; NEILS, Moriah; NEWELL, Bryce Clayton; GOMEZ, Ricardo. Fotohistorias: Participatory Photography as a Methodology to Elicit the Life Experiences of Migrants. 48th Hawaii International Conference on System Sciences [HICSS-48], Kauai-HI, IEEE Computer Society, 2015, pp.3672-3681 [https://ieeexplore.ieee.org/document/7070258 - acceso en 02 de marzo de 2020]. 